\title{
OS PARADIGMAS DE "TU" E "VOCÊ" NO CONTEXTO DATIVO NAS CARTAS PERNAMBUCANAS
}

\author{
PARADIGMS OF "TU" AND "VOCÊ" IN THE DATIVE CONTEXT IN \\ PERNAMBUCAN LETTERS
}

\author{
Helder Aquino de Melo ${ }^{1}$ \\ Valéria Severina Gomes ${ }^{2}$
}

\begin{abstract}
RESUMO: O presente artigo dá continuidade a estudos prévios acerca do Português Brasileiro (PB), no tocante à inserção do "você" no paradigma pronominal e seu encaixamento nos demais contextos sintáticos (GOMES, 2014; LOPES et al, 2018). Nesse sentido, visa ampliar os resultados desses estudos com a abordagem da relação sintática dativa em manuscritos pernambucanos dos séculos XIX e XX, tanto do ponto de vista do fator estrutural quanto social (LABOV, WEINREICH e HERZOG, 2006). Para essa discussão, tomou-se por base também a teoria do Poder e da Solidariedade (BROWN e GILMAN, 1960), a Teoria da Polidez (BROWN e LEVINSON, 1987) e os Padrões Sociolinguísticos (LABOV, 2008). Inicialmente, foi feita a reconstrução da performance desses documentos, considerando as condições em que foram produzidos, o perfil dos missivistas e a relação com os seus interlocutores, discutindo os fatores sociais e pragmáticos. Em seguida, verificou-se o processo de variação dos pronomes pertencentes aos paradigmas do "tu" e "você" no contexto morfossintático dativo. Um dos resultados aponta que as escolhas das formas pronominais estão diretamente vinculadas ao tipo de relação estabelecida entre os missivistas, considerando o uso do dativo em correlação com cada subgênero analisado.
\end{abstract}

PALAVRAS-CHAVE: Carta pessoal. Tu e você em contexto dativo. Fatores sociais. Fatores formais.

ABSTRACT: This article continues previous studies on Brazilian Portuguese (PB) about the insertion of "você" in the pronominal paradigm and its fitting into other syntactic contexts (GOMES, 2014; LOPES et al, 2018). In this sense, it aims to expand the results of these studies with the approach of the dative syntactic relationship in Pernambucan manuscripts of the 19th and 20th centuries, both from the point of view of the structural and social factor (LABOV, WEINREICH and HERZOG, 2006). For this discussion, the theory of Power and Solidarity (BROWN and GILMAN, 1960), the Theory of Politeness (BROWN and LEVINSON, 1987) and Sociolinguistic Standards (LABOV, 2008) were also based. Initially, the reconstruction of the performance of these documents was made, considering the conditions in which they were produced, the profile of the correspondents and the relationship with their interlocutors, discussing the social and pragmatic factors. Then, the process of variation of the pronouns belonging to the "tu" and "você" paradigms in the dative morphosyntactic context was analyzed. One of the results points out that the choices of the pronoun forms are directly linked to the type of relationship established between the letter writers, considering the use of the dative in correlation with each subgenre analyzed.

KEYWORDS: Personal letter. Tu and você in dative context. Social factors. Formal factors.

\footnotetext{
${ }^{1}$ Mestrando do Programa de Pós-Graduação em Estudos da Linguagem da Universidade Federal Rural de Pernambuco (UFRPE). Graduado em Letras Português e Espanhol pela Universidade Federal Rural de Pernambuco (UFRPE). Membro do Grupo de Pesquisa Tradições Discursivas do Ceará (TRADICE/UFC) e do Grupo de Pesquisa Estudos da Língua em Uso (ELU/UFRPE). E-mail: he7der@gmail.com

${ }^{2}$ Professora do Programa de Pós-graduação em Estudos da Linguagem (PROGEL). Professora do Departamento de Letras Português e Espanhol da Universidade Federal Rural de Pernambuco (UFRPE). E-mail: lelavsg@gmail.com
} 
Volume 15 - Número 1 - jan/jul de 2020

\section{Introdução}

As pesquisas acerca da historicidade da língua e do texto vêm ganhando projeção e adeptos nos últimos anos no cenário nacional. Nesse ambiente de avanços e de articulações de estudos recentes sobre a dinâmica da língua portuguesa em correlação com a natureza dos textos, partilhamos da ideia de que as contribuições dessa área têm agregado diferentes perspectivas no âmbito acadêmico, com implicações significativas para as reflexões no âmbito pedagógico. Essas contribuições se evidenciam por meio da análise sistemática de ocorrências linguísticas do passado que ainda estão em uso no presente, de formas linguísticas em duelo e de formas que deixaram de ser usadas. Dentro desse processo de variação e mudança do português brasileiro, abordamos neste artigo, as formas dos paradigmas do tu e do você no contexto morfossintático dativo, em cartas pessoais pernambucanas dos séculos XIX e XX. O nosso propósito é contribuir para os estudos prévios sobre a configuração do português brasileiro, no que diz respeito às formas pronominais, acrescentando dados de Pernambuco.

O presente estudo segue a linha de trabalhos prévios realizados por integrantes do Projeto Para a História do Português Brasileiro, como: "A reorganização do sistema pronominal de $2^{\text {a }}$ pessoa na história do português brasileiro: outras relações gramaticais" (LOPES et al., 2018) e "Ação - Formulação - Tradição: A correspondência de Câmara Cascudo a Mario de Andrade de 1924 a 1944, entre proximidade e distância comunicativa" (COSTA, 2012). O primeiro aborda os reflexos da reorganização do sistema pronominal nas relações gramaticais e o segundo analisa as características da natureza das cartas pessoais trocadas por dois missivistas ilustres. Analisar as ocorrências dos paradigmas de $t u$ e você no contexto dativo em cartas pernambucanas sinaliza a convergência do presente estudo com os dois mencionados anteriormente. Nesse sentido, o objetivo deste artigo é analisar a produtividade do contexto morfossintático dativo por meio dos padrões de comportamento dos paradigmas de $t u$ e você, identificados nas cartas pessoais pernambucanas, correlacionando a variação linguística (LABOV, WEIRICH e HERZOG, 2006; LABOV, 2008), a natureza do texto (KOCH, 1997; COSTA, 2012) e o tipo de relação entre os missivistas (BROWN e GILMAN , 1960; BROWN e LEVINSON, 1987).

A amostra utilizada para a análise é constituída por 185 cartas pessoais escritas entre 1867 e 1996, sendo 29 cartas pessoais escritas no século XIX e 156 cartas escritas no século XX, totalizando 185 cartas pessoais pernambucanas divididas nos seguintes subgêneros: cartas de amor (59), cartas de amigo (38) e cartas de família (88). A expressiva diferença numérica entre os dois séculos se dá em virtude da dificuldade de encontrar cartas do século XIX, pois muitos desses documentos foram extraviados e destruídos pelas más condições de armazenamento. Nesse caso, tentaremos fazer bom uso desses dados, como é corriqueiro nos estudos sócio-históricos, superando o desafio de fazer uma discussão qualitativa e quantitativa com um corpus heterogêneo. Se, por um lado, esse desequilíbrio pode ser problemático, por outro lado, trata-se de um corpus representativo de missivistas ilustres e não ilustres, com diferentes níveis de letramento, situados em Recife e na região metropolitana. Esses dados são relevantes para a verificação do duelo entre o tu e o você no cenário temporal e espacial delineado.

Para essa discussão, o presente artigo está organizado em dois pilares: o primeiro, sobre os fatores sociais, reconstrói a performance da carta pessoal, traça um breve panorama acerca dos níveis (proximidade e distância) e tipos de relação simétrica e assimétrica entre os missivistas; e o segundo pilar traz uma análise acerca das formas dos paradigmas de $t u$ e você 
Volume 15 - Número 1 - jan/jul de 2020

no contexto morfossintático dativo, explicitando como essa relação sintática se mostra produtiva ou não à inserção do você no quadro pronominal do português brasileiro.

\section{Reconstrução da performance das cartas pernambucanas}

Para a reconstrução da performance das cartas, partimos da delimitação dos subgêneros que compõem o corpus, que são: cartas de amor, cartas de amigo e cartas de família. É importante perceber que não se trata, apenas, de um rótulo para reunir as cartas em categorias. Essas especificidades do agrupamento de cartas pessoais estão diretamente relacionadas ao propósito comunicativo e à natureza constitutiva dessas missivas. A carta pessoal é uma forma de comunicação influenciada por características informais e espontâneas, por isso, muito apreciada nos estudos linguísticos para a composição de um corpus histórico (COSTA, 2012). As cartas pessoais são essencialmente marcadas pela espontaneidade, proximidade comunicativa e por diferentes níveis de intimidade entre remetente e destinatário (SOUZA, 2012). A discussão acerca da performance das cartas passa por dois vieses: os níveis de proximidade e distância comunicativa e os tipos de relação entre os missivistas (simetria/assimetria).

\subsection{Proximidade e distância comunicativas}

Como todo modo tradicional de dizer, histórico e culturalmente empregado, que vai de uma saudação a um gênero de texto, a carta pessoal está situada no continuum proximidadedistância. Koch (1997, p. 7) afirma que "toda tradição discursiva possui um perfil de concepção discursiva, quer dizer, pode-se identificar seu espaço no continuum proximidade-distância, que em princípio é independente de seu perfil medial", ou seja, fônico ou gráfico. Dessa forma, as características que tendem à informalidade presentes na carta pessoal conferem a esse gênero mais traços paramétricos de proximidade. Dentre esses, traços podem ser destacados: privacidade, intimidade, emocionalidade, envolvimento de situações e atos, possibilidade de referenciação em relação à origem do falante, proximidade física, cooperação entre falante/ouvinte, dialogicidade, espontaneidade e desenvolvimento livre de temas.

Considerar o caráter da carta pessoal como sendo uma "conversação escrita" (GOMES, 2014, p. 40) permite observarmos como as propriedades predominantes da proximidade comunicativa podem ser definidas de acordo com as condições de produção. Por se tratar de um gênero com fortes componentes de espontaneidade, de acordo com Gomes (2014, p. 40), "favorece a proximidade comunicativa no que diz respeito à privacidade, à familiaridade entre os interlocutores, à emocionalidade, à espontaneidade relativa e ao desenvolvimento temático livre".

Com relação à distância comunicativa podemos destacar os seguintes traços paramétricos: publicidade, anonimicidade, pouca/nenhuma emocionalidade, impossibilidade do envolvimento de situações/atos, impossibilidade da referenciação em relação à origem do falante, distância física, pouca cooperação, monologicidade, planejamento, fixação de temas, entre outros. Essas características não são tão comuns ao gênero carta pessoal, pois as influências emocionais na interação entre os missivistas são próprias da natureza desse gênero.

A proximidade comunicativa é um traço predominante nas cartas de amor e de família. Por se tratar de correspondências entre irmãos, cônjuges, pais e filhos há uma intimidade maior, 
Volume 15 - Número 1 - jan/jul de 2020

permitindo uma linguagem informal. Os apelidos carinhosos e diminutivos encontrados nos vocativos são evocados exatamente pela intimidade existente entre os interlocutores.

(1) Querida filhinha Yayá. Escrevi-[te] a 21 deste pelo "Cor-delliere" e hoje novamente escrevo-te pelo "Magdalena" para dar-te a compensação de não teres recebido cartas pelo Da-nubé (José Mariano 05 - 1900)

(2) Queridinha N. A paz do Senhor N. e com o maior prazer pego nesta fraca pena para responder a tua a dorada cartinha (NJ 22 - 1950)

As cartas de amigo analisadas, embora algumas apresentem certas características de formalidade, visavam ao estreitamento do contato com os leitores, mesclando a formalidade com as ocorrências de dialogicidade, emocionalidade e coloquialidade a depender da relação estabelecida entre os interlocutores e do assunto tratado. Abaixo seguem dois trechos de cartas pessoais trocadas entre amigos, nos quais é possível observar uma polidez maior, por se tratar de assunto profissional, conforme exemplos (3) e (4) selecionados:

(3) Meu caro Paranhos, Quero ter o prazer de apresentar-lhe o meu amigo dezembargador Domingos Alves Ribeiro. É um dos meus| mais íntimos amigos, e devo essa amizade ao Dantas, e tambem, indireta-mente, ao José Bonifacio. (Joaquim Nabuco 15 - 1904)

(4) Meu caro Dr. Velloso, Amanhã devo chegar ahí ás 9.10 na estação da Baltimore and Ohio R.R. Queria avisar o Mengoli e fazer guardar-me no hotel o mesmo aposento que tive. Faça me o favor de suspender a remessa de correspondencia para New York (Joaquim Nabuco - 16 - 1905)

Nesses dois exemplos, é perceptível uma relação respeitosa por parte do missivista, evidenciada nos trechos em negrito. Quando os missivistas iniciam com "Meu caro..." e "Meu caro Dr." mostram uma forma cerimoniosa e, ao mesmo tempo, um distanciamento entre os interlocutores. A inserção dos títulos "Dr." e "desembargador" também induz a um tratamento mais formal próprio do início do século XX, conforme a datação das duas cartas mencionadas. A forma pronominal adotada pelos missivistas foi o você, cujo paradigma se mantém no clítico the e no modo verbal imperativo. O emprego do você nas cartas analisadas mostra o seu hibridismo, ora usado nas relações de maior distanciamento, ora usado em situações de maior proximidade entre os interlocutores, disputando com o $t u$ íntimo, os espaços nas relações de intimidade entre pai, filho, cônjuges, irmãos ou outro grau de parentesco. Vejamos em destaque, nos exemplos a seguir, o emprego de tu e você em cartas de família e cartas de amor:

(5) Eu penso em te mandar novamente ao Rio quando eu chegar la e vai tu pensando na mesma cousa e te preparando para a viagem (Manoel Borba para sua filha - 15-1926)

(6) Fiquei muito alegre em saber que tú vem passar são joão comigo manda-me dizer o dia porque se for possivel eu vou te esperar se for possivel eu vou te esperar Z ( $\mathrm{N}$ para seu noivo $\mathrm{J}-01-1949$ ) 
Volume 15 - Número 1 - jan/jul de 2020

(7) Como é que você então tomou por outro lado o que eu quis dizer? Ou é que eu me exprimi mal? Eu disse, como você poderá ver se ainda tiver as cartas passadas (Waldemar de Oliveira para sua mãe $-27-1917$ )

(8) Minha Mãe. Os meus atrapalhos tem sido tantos que nem sei mesmo mais quando foi que escrevi para vocês. Imagino que nem lhe disse que tinha recebido tudo que você mandou por Ubaldo (Arthur Orlando para sua mãe - 22 - 1929)

Para analisar as formas dos paradigmas de tu e você é fundamental incluir as relações estabelecidas entre os missivistas (Quem escreveu? Para quem? Quando? Onde?), como também as características do gênero analisado. No caso de uma abordagem sócio-histórica, a peça teatral e a carta pessoal (na Retórica, denominada epistola familiaris) expressam o uso mais espontâneo que podemos recuperar, quando direcionamos o olhar para o passado mais distante. A influência das características informais ocorre justamente porque esses gêneros de natureza conversacional são marcados por traços de proximidade.

Em se tratando do gênero carta pessoal, "é o relacionamento entre os interlocutores que define o espaço que uma determinada carta pessoal poderá ocupar entre os diversos agrupamentos de cartas pessoais" (COSTA, 2012, p. 145). Sendo assim, os níveis de proximidade e distância comunicativas estão inteiramente ligados com o subgênero das cartas, que neste estudo foram: cartas de amor, cartas de amigo e cartas de família.

\subsection{As relações de simetria e assimetria entre os missivistas}

Além dos níveis de proximidade e distância, é importante levarmos em consideração, nas condições de produção das cartas, se a relação estabelecida entre os interlocutores é de simetria ou assimetria. Essas relações são identificadas por meio das estratégias linguísticas utilizadas pelos interlocutores. As cartas de amor e de amigo normalmente apresentaram relações simétricas, enquanto as cartas de família apresentaram relações assimétricas ascendentes (filho para pai) e relação assimétrica descendente (pai para filho).

Portanto, a relação entre os missivistas e seus destinatários pode ser: (9) assimétrica descendente (de superior para inferior: pai-filho, mãe-filho); (10) assimétrica ascendente (de inferior para superior: filho-pai, filho-mãe); (11) simétrica ou solidária (entre amigos, entre os integrantes de um casal). Vejamos os seguintes exemplos:

(9) Ignes Recebi [tua] carta trasida pelo Gatemi ele e antes havia recebido a pasta de papeis vinda pelo Costeira. (...) Todos enviam Lembranças e me deram para te enviar os retratos de Conrrado e da familia. Adeus. Lembranças e saudades a todos. Pai e amigo M. Borba. (Manoel Borba - 13 - 1925)

(10) Minha boa mãe. Abençoe-me. O portador desta é Chico, que, no Olinda amanhã par-te para ahi. (...) Por hoje, fico aqui Saudades á todos em geral. Abraços e beijos o teo filho do co-ração. Mario Sette (Mário Sette - 02 - 1906)

(11) Aurorinha, Minha santinha adorada. Saudades.A missa da festa de Nossa Senhora Auxiliadora será ás 8 horas. Portanto, minha bonequinha, passarei entre 7 e 20 e 7 1 12 (...). Até amanhã minha noivinha. Não esquece o louco amor do teu, só teu Nelsinho. P.S. Meu 
Volume 15 - Número 1 - jan/jul de 2020

amor onde está escripto nella omittidos, leia-se nella emittido. Mais saudades do Nelsito (Nelson Ferreira - 01 - 1025)

Quando há uma distinção hierárquica na interação trata-se das relações assimétricas, pois nesse tipo de relação, de acordo com Souza (2012, p. 56), o "falante/remetente e ouvinte/destinatário devem estar em níveis hierárquicos distintos". É nessa distinção que a relação assimétrica se divide em descendente (de superior para inferior) (9), ascendente (de inferior para superior) (10). Numa relação assimétrica é possível identificar uma relação de poder entre os missivistas. Sob essa perspectiva, a estratégia da polidez (BROWN e LEVINSON, 1987), expressa na forma de tratamento, é identificada e "evitaria o conflito entre os interactantes" (GOMES, 2014, p. 42).

Ressaltamos que a dicotomia do "poder e solidariedade" postulada por Brown e Gilman (1960) é evidenciada na relação social existente entre o remetente e o destinatário. Diferentes formas de tratamento são eleitas em função da hierarquia estabelecida entre os interlocutores, pois a relação de poder entre duas pessoas não é recíproca. O parâmetro da solidariedade corresponde à igualdade na relação mantida entre as pessoas, pois estão no mesmo nível hierárquico social.

Essas relações simétricas são também conhecidas como solidárias por estabelecerem uma igualdade na relação (11), permitindo um sentimento de solidariedade entre os participantes. Para Souza (2012, p. 57), "as relações simétricas são aquelas em que existe, ou se percebe, igualdade funcional e de papéis sociais entre os participantes da interação (idade, gênero ou profissão)".

O processo de reconstrução da performance das cartas pessoais possibilita traçar as condições de produção das correspondências. A seguir, apresentaremos um breve panorama dos estudos do contexto morfossintático dativo em cartas pessoais de acordo com os subgêneros.

\section{As formas dos paradigmas de tu e você no contexto morfossintático dativo}

O uso do dativo apresenta diversas peculiaridades, uma vez que se trata de um complemento verbal parcialmente contemplado pela gramática tradicional sob o rótulo de objeto indireto em virtude exclusivamente da sua conexão indireta ao predicador verbal através de uma preposição. Ao falarmos sobre o dativo, é importante ressaltar que este contexto morfossintático não deve ser considerado apenas quando há uma preposição presente, pois de acordo com Souza e Oliveira (2013, p. 102), o dativo "não apresenta preposição quando se realiza sob a forma de um clítico átono (Eu lhe dei um presente)". Sintaticamente, a expressão do dativo se dá quando o complemento que é projetado por predicadores verbais de dois ou três lugares e é cliticizável através do pronome lhe (RUMEU; OLIVEIRA, 2016, p. 35).

Sabemos que a posição de sujeito foi favorável à inserção do você no paradigma pronominal do português brasileiro, contudo, assim como pesquisas anteriores investigaram (RUMEU e OLIVEIRA, 2016; LOPES et al, 2018), é necessário acompanhar o encaixamento do você nos demais contextos morfossintáticos, a exemplo da estratégia dativa.

Nesse sentido, buscamos trazer evidências empíricas acerca do grau de inserção do você no contexto dativo. Com base nos resultados divulgados por Gomes e Lopes (2014), neste trabalho, ampliamos o corpus com cartas pernambucanas de escreventes não ilustres, desejando responder às seguintes questões: qual a produtividade do você no contexto dativo em correlação com o tipo de sujeito utilizado nas cartas, seja uma carta escrita do começo ao fim com "tu- 
Volume 15 - Número 1 - jan/jul de 2020

exclusivo", com "você-exclusivo" ou com a mistura de "tu-você"? Qual a produtividade do você no contexto dativo em correlação com e o subgênero (carta de amigo, de família e de amor)?

De acordo com Weinreich; Labov; Herzog (2006, p. 122), a mudança linguística ocorre em 3 partes: "(1) à medida que um falante aprende uma forma alternativa, (2) durante o tempo em que as duas formas existem em contato dentro de sua competência, e (3) quando uma das formas se torna obsoleta". A análise do comportamento dos paradigmas de tu e você diante da produtividade do dativo nas cartas pessoais pernambucanas registra variantes que passaram pela fase (1) e se encontram na fase (2), na qual as duas formas existem em contato. A sistematização deste tópico parte da análise dos fatores formais para os fatores sociais relacionados aos subgêneros das cartas.

\subsection{Análise das ocorrências de dativo}

Analisamos as ocorrências das formas concretas dos paradigmas tu e você realizadas de acordo com a função sintática dativa, considerando o tratamento na posição de sujeito. Foram computadas 543 ocorrências dativas distribuídas entre as formas: te, lhe, a você, para você, preposição+você, a ti, para ti e preposição $+t i$.

Na tabela 1, encontra-se a distribuição das formas pronominais de segunda pessoa na posição de dativo em cartas pernambucanas, em relação às ocorrências de sujeito. Há cartas escritas exclusivamente com o emprego do $t u$ como sujeito, cartas com o uso exclusivo de você, do início ao fim, e cartas escritas com a mistura dos dois paradigmas, tu e você na posição de sujeito.

Tabela 1: Distribuição da função dativa e o uso do sujeito.

\begin{tabular}{|c|c|c|c|c|c|c|c|c|c|}
\hline Nominativo & \multicolumn{9}{|c|}{ Formas dativas de segunda pessoa } \\
\hline $\begin{array}{c}\text { Simetria do } \\
\text { tratamento } \\
\text { (sujeito) }\end{array}$ & Te & Lhe & A você & $\begin{array}{l}\text { Para } \\
\text { você }\end{array}$ & $\begin{array}{c}\text { Prep.+ } \\
\text { você }\end{array}$ & A ti & $\begin{array}{c}\text { Para } \\
\text { ti }\end{array}$ & $\underset{\text { ti }}{\text { Prep. }}+$ & Total \\
\hline Você-exclusivo & $\begin{array}{c}57 \\
20 \%\end{array}$ & $\begin{array}{c}168 \\
59 \%\end{array}$ & $\begin{array}{c}19 \\
6,6 \%\end{array}$ & $\begin{array}{c}27 \\
9,4 \%\end{array}$ & - & $\begin{array}{c}2 \\
0,7 \%\end{array}$ & $\begin{array}{c}1 \\
0,3 \%\end{array}$ & $\begin{array}{c}11 \\
3,8 \%\end{array}$ & $\begin{array}{c}285 \\
52,5 \%\end{array}$ \\
\hline Tu-exclusivo & $\begin{array}{c}49 \\
72 \%\end{array}$ & $\begin{array}{c}2 \\
2,9 \%\end{array}$ & - & $\begin{array}{c}2 \\
2,9 \%\end{array}$ & - & $\begin{array}{c}3 \\
4,4 \%\end{array}$ & - & $\begin{array}{c}12 \\
17,4 \%\end{array}$ & $\begin{array}{c}68 \\
12,5 \%\end{array}$ \\
\hline Tu e você & $\begin{array}{c}102 \\
53,6 \%\end{array}$ & $\begin{array}{c}33 \\
17,3 \%\end{array}$ & $\begin{array}{c}5 \\
2,6 \%\end{array}$ & $\begin{array}{c}11 \\
5,8 \%\end{array}$ & - & $\begin{array}{c}6 \\
3,1 \%\end{array}$ & $\begin{array}{c}2 \\
1 \%\end{array}$ & $\begin{array}{c}31 \\
16,3 \%\end{array}$ & $\begin{array}{l}190 \\
35 \%\end{array}$ \\
\hline Total & $\begin{array}{c}208 \\
38,3 \%\end{array}$ & $\begin{array}{c}203 \\
37,3 \%\end{array}$ & $\begin{array}{c}24 \\
4,4 \%\end{array}$ & $\begin{array}{c}40 \\
7,3 \%\end{array}$ & - & $\begin{array}{c}11 \\
2 \%\end{array}$ & $\begin{array}{c}3 \\
0,6 \%\end{array}$ & $\begin{array}{c}54 \\
10 \%\end{array}$ & $\begin{array}{c}543 \\
100 \%\end{array}$ \\
\hline
\end{tabular}

Fonte: os autores

De um modo geral, podemos observar, na tabela 1, que as formas clíticas te e lhe representam a maior parte das ocorrências de dativo nas cartas pessoais analisadas. Esses dados mostram a predominância dos clíticos na construção dativa e a disputa dos paradigmas $t u$ e você nessas construções. Seguiremos analisando cada forma dativa de acordo com a ordem estabelecida na tabela 1.

O clítico te mostrou-se resistente no resultado obtido, pois mesmo disputando com o paradigma de você, superou o resultado do uso do clítico lhe, totalizando 208 ocorrências e 
Volume 15 - Número 1 - jan/jul de 2020

ocupando $38,3 \%$ do total quantificado. Importa salientar que o clítico te teve sua distribuição bem mais acentuada em cartas com sujeito tu-exclusivo $(72 \%)$, o que mostra a tendência conservadora no uso do dativo de acordo com o sujeito escolhido pelo missivista. Nas cartas com o sujeito você-exclusivo, mesmo alcançando um número alto de ocorrências, não conseguiu disputar com o paradigma de você e obteve apenas $20 \%$ das ocorrências nas cartas com sujeito voce-exclusivo. Quando se trata da mistura no sujeito, $t u$ e você, o clítico te se mostra mais frequente, com 102 ocorrências, tendo em vista que ocupou 53,6\% do total de cartas escritas com mistura nas formas pronominais.

(12) querido Z. a paz do Senhor. Escrevi relatando-te as saudades (NJ - 04 - 1949)

Em (12) é possível observar o clítico te no início de uma carta. É comum que esse clítico apareça na forma de ênclise, os principais verbos no gênero carta de amor que evocam esse tipo de ocorrência são: escrever, enviar e relatar. Em relação aos dados do Rio de Janeiro (LOPES et al, 2018, p. 164), por exemplo, no caso do tu-exclusivo e da mistura entre tu e você, foi mais frequente a variante te (78\% e $70 \%$ respectivamente), coincidindo com Pernambuco. Quanto ao sujeito você-exclusivo, os dados do Rio de Janeiro mostraram um certo equilíbrio entre o clítico te $(31 \%)$ e o lhe $(27 \%)$. Já em Pernambuco, o clítico te mostrou-se menos resistente.

Conforme a tabela 1 , o clítico lhe totalizou $37,3 \%$ das ocorrências do dativo, um número de casos aproximado ao te (38,3\%). De acordo com Lopes et al (2018, p. 164), em São Paulo, o clítico te também prevaleceu ao lado de lhe com os mesmos percentuais (44\%). O clítico lhe mostra-se mais recorrente em cartas escritas com você-exclusivo na posição de sujeito, computando 168 ocorrências (59\%) nesse fator. Nas cartas de tu-exclusivo, o clítico lhe só apareceu duas vezes, representando $2,9 \%$. Nas cartas com mistura de $t u$ e você o clítico lhe ocupou 17,3\%, com 33 ocorrências.

(13) não é assim querido? sim Z. eu estou le esperando agora no prosimo dia 17. sinto muito não poder le esperar. (NJ - 04 -1949)

Em (13) observamos como o clítico lhe aparece na posição proclítica, ao contrário do que ocorre com frequência em te, nas cartas analisadas, o clítico "lhe" é mais produtivo antes do verbo principal. Podemos observar em (13) a supressão do "h" na grafia do clítico, indicando uma forma recorrente na escrita da missivista do litoral pernambucano, que tende a transportar para a escrita marcas da fala.

O dativo também se apresenta como um sintagma preposicionado como em: a você, para você, preposição + você, a ti, para ti e preposição $+t i$. Vejamos a discussão a seguir de cada forma.

Em se tratando do dativo apresentado como sintagma preposicionado, podemos observar que a forma $a$ você, ocupando $4,4 \%$ das ocorrências, é predominante nas cartas com o sujeito você-exclusivo $(6,6 \%)$, seguida das cartas com a mistura entre tu e você $(2,6 \%)$. Nas cartas com sujeito tu-exclusivo, não houve ocorrências desse fator, mostrando que há uma predominância dos paradigmas de $t u$ em cartas com sujeito tu-exclusivo. Vejamos:

(14) Elles quizerem, principalmente o primeiro que eu possa indicar os nomes dos amigos a você. (Arthur Orlando - 3 - 1894) 
Volume 15 - Número 1 - jan/jul de 2020

O uso de "a você" em (14) aparece no final da oração, essa posição é recorrente nesse tipo de construção dativa nas cartas que possuem exclusividade tratamental em você e mistura entre tu e você.

Com relação à forma para você, essa ocupou 7,3\% do quantitativo geral e se mostrou mais predominante em cartas pessoais escritas com o sujeito você-exclusivo $(8,2 \%)$, seguido também pelas cartas escritas com mistura de tu e você (5\%). Somente $2 \%$ das ocorrências de para você apareceram nas cartas com sujeito tu-exclusivo, confirmando a tendência do uso do paradigma de acordo com o sujeito selecionado pelo missivista. Segue o exemplo:

(15) Diz você que (...) precipitação ou vontade de acabar quando escrevi para você. (Waldemar de Oliveira - 12 - 1916)

Assim como em (14), o exemplo (15) segue o padrão do dativo preposicionado que aparece no final da oração. Também é comum, de acordo com o nível de escolaridade do missivista, a ocorrência de pra você, trazendo marca da oralidade na escrita com a supressão do primeiro $a$. Em correlação com dados de outros estados, é interessante comentar que o sintagma a você e para você apresentou maior incidência nas cartas potiguares, no estudo comparativo feito por Lopes et al (2018, p. 161). Nas cartas de Pernambuco não foram encontrados casos de dativos preposicionados no paradigma de você.

Voltando para o paradigma de $t u$, observamos aqui as ocorrências de dativo realizadas por meio do sintagma preposicionado a ti, este ocupando apenas $2 \%$ da totalidade obtida. Nas cartas com o sujeito você-exclusivo, esse tipo de construção totaliza $0,6 \%$ das ocorrências. Em se tratando das cartas com sujeito tu-exclusivo, a realização dessa forma é mais expressiva, alcançando 4,4\%. Quando há mistura entre as formas dos paradigmas de $t u$ e você, a forma $a t i$ ocupa 3,1\%. A seguir observemos um exemplo retirado de uma carta de amor escrita em 1949:

(16) Vou terminar enviando a paz A ti. (NJ - 11 - 1949)

Podemos observar em (16) que a forma dativa a ti aparece também no final da oração, como a maioria das formas dativas não cliticizadas. A mescla entre letras maiúsculas e minúsculas é comum na escrita dessa missivista, o que é um indício de sua pouca habilidade com a escrita.

Seguindo a análise das ocorrências dos sintagmas preposicionados na posição dativa, observamos agora os resultados do dativo na forma para ti, ocupando apenas $0,6 \%$ das ocorrências. Nas cartas com o sujeito você-exclusivo a construção para ti ocupou $0,3 \%$, seguido de $1 \%$ das ocorrências em cartas com mistura de tu e você. Interessa observar que, em cartas escritas com sujeito tu-exclusivo, não houve ocorrência desse tipo de construção, essa baixa produtividade segue o padrão do resultado exposto anteriormente, com a forma $a \mathrm{ti}$, mostrando que esses dois tipos de construções dativas são pouco escolhidos pelos missivistas selecionados. Vejamos um exemplo escrito em 1950:

(17) Querida N. nu momento em que pego nesta pena para ti escrever. (NJ - 20 - 1950)

Em (17) observamos como a missivista retrata na sua escrita a forma como o clítico te soa na oralidade, sendo escrito com - $i$ ao invés do - $e$. Nas cartas dessa missivista, é comum observarmos esse tipo de troca fonética, pois sua escrita é menos monitorada, uma vez que se trata de uma missivista jovem e com baixo grau de escolaridade. 
Volume 15 - Número 1 - jan/jul de 2020

Por fim, as formas dativas que têm como antecessoras preposições diferentes de $a$ ou para resultaram em $10 \%$ dos dados. As formas realizadas com preposição $+t i$ em cartas com sujeito você-exclusivo alcançaram apenas $3,8 \%$ das ocorrências, o que mostra a baixa produtividade dessa forma diante de um sujeito diferente. Quando observamos o resultado das ocorrências em cartas com sujeito tu-exclusivo, esse número já aparece de maneira mais expressiva, alcançando 17,4\% das ocorrências. Nas cartas com mistura no sujeito em tu e você, as ocorrências de sintagmas preposicionados $+t i$ ocuparam $16,3 \%$ da totalidade. Na carta escrita em 1950, podemos observar:

(18) Eu fico nu teu esquecimento quem não si esquecer di ti um so momento. (NJ - 20 1950)

Em (18) podemos observar o uso da preposição de motivada pela regência do verbo esquecer, assim como ocorre com frequência depois com o verbo lembrar. Mais uma vez observamos uma troca fonética, dessa vez na preposição de que foi escrita com $-i$, marcando a forma pronunciada pela missivista selecionada.

No que diz respeito ao uso das formas do paradigma de você, o clítico lhe, no contexto morfossintático dativo foi mais expressivo nas cartas com sujeito você-exclusivo, contemplando $59 \%$, totalizando 168 ocorrências. Esse resultado aponta para uma maior inserção das formas do paradigma do você em produções onde o sujeito era você-exclusivo. No tópico seguinte será possível analisarmos a relação entre os subgêneros das cartas pessoais (cartas de família, cartas de amigo e cartas de amor) e as formas dativas de segunda pessoa.

\subsection{A produtividade do dativo nos subgêneros das cartas pessoais pernambucanas}

Silva (2018, p. 73) afirma que "o agrupamento das cartas de acordo com o subgênero auxilia na identificação, nos textos, dos modos de dizer, ou seja, estratégias linguísticodiscursivas recorrentes". Partindo dessa premissa, consideramos relevante fazer o cruzamento das formas dativas de segunda pessoa com os subgêneros das cartas pessoais selecionadas, pois sabemos que os tipos e níveis de relações estabelecidas entre os missivistas detêm uma enorme influência nas escolhas pronominais feitas por eles.

Dando continuidade às particularidades do contexto morfossintático dativo, a tabela a seguir mostra a produtividade do dativo (te, lhe, a você, para você, prep.+você, a ti, para ti, prep $+t i$ ) de acordo com cada subgênero (amigo, familia e amor) das cartas pessoais:

Tabela 2: As relações dos subgêneros das cartas pessoais com as formas dativas de $2^{\mathrm{a}}$ pessoa

\begin{tabular}{|c|c|c|c|c|c|c|c|c|c|}
\hline Subgêneros & \multicolumn{7}{|c|}{ Formas dativas de segunda pessoa } \\
\hline $\begin{array}{c}\text { Simetria do } \\
\text { tratamento (sujeito) }\end{array}$ & Te & Lhe & A você & $\begin{array}{c}\text { Para } \\
\text { você }\end{array}$ & $\begin{array}{c}\text { Prep+ } \\
\text { você }\end{array}$ & A ti & $\begin{array}{c}\text { Para } \\
\text { ti }\end{array}$ & Prep. + ti & Total \\
\hline Cartas de Família & $\begin{array}{c}28 \\
19,3 \%\end{array}$ & $\begin{array}{c}94 \\
65 \%\end{array}$ & $\begin{array}{c}6 \\
4,1 \%\end{array}$ & $\begin{array}{c}12 \\
8,3 \%\end{array}$ & - & $\begin{array}{c}2 \\
1,4 \%\end{array}$ & - & 3 & 145 \\
\hline Cartas de Amigo & 14 & 64 & 10 & 6 & - & 1 & - & 5 & 100 \\
& $14 \%$ & $64 \%$ & $10 \%$ & $6 \%$ & $-7 \%$ & $1 \%$ \\
\hline Cartas de Amor & 166 & 45 & 8 & 22 & - & 8 & 3 & 46 & 298 \\
& $55,7 \%$ & $15,1 \%$ & $2,7 \%$ & $7,4 \%$ & - & $2,7 \%$ & $1 \%$ & $15,5 \%$ & $54,9 \%$ \\
\hline
\end{tabular}


Volume 15 - Número 1 - jan/jul de 2020

\begin{tabular}{|c|c|c|c|c|c|c|c|c|c|}
\hline Total & 208 & 203 & 24 & 40 & - & 11 & 3 & 54 & 543 \\
& $38,3 \%$ & $37,4 \%$ & $4,4 \%$ & $7,4 \%$ & - & $2 \%$ & $0,6 \%$ & $10 \%$ & $100 \%$ \\
\hline
\end{tabular}

Fonte: os autores.

Nas cartas de família, a forma dativa com maior número realizado foi o clítico the (65\%), com 94 de um total de 145 ocorrências de dativo. O clítico te (19,3\%) ficou em segundo lugar, porém seu número bastante inferior ao uso do the mostra que o uso do paradigma de você ganhou mais espaço nesse subgênero, possivelmente por se tratar de um subgênero que lida com relações assimétricas ascendente e descendente (de filho para pai, de pai para filho). As formas dativas a você $(4,1 \%)$, para você $(8,3 \%)$, tiveram um desempenho menor em comparação aos clíticos te e lhe, assim como a ti $(1,4 \%)$, preposição $+t i(2,1 \%)$ e para ti, com nenhuma ocorrência.

Quanto às cartas de amigo, a forma dativa mais produtiva foi no uso do clítico lhe (65\%), mostrando que, assim como nas cartas de família, o comportamento do dativo continua mais produtivo dentro do paradigma de você. O clítico te (14\%) se manteve presente, mesmo computando 14 ocorrências. A forma $a$ você (10\%) conseguiu um maior espaço nesse subgênero do que no anterior, disputando com a forma a ti, que só representou $1 \%$ da totalidade nesse segmento. Para você (6\%) e para ti (não computou), preposição $+t i(5 \%)$ ficou em último lugar na preferência. Seguindo o mesmo padrão do subgênero carta de família, a predominância do paradigma de você mostra o caráter híbrido dessa forma pronominal, ora mais cerimoniosa, ora disputando espaços de intimidade com o $t u$, em se tratando de um subgênero marcado pela simetria no tratamento.

Nas cartas de amor, o resultado foi bem mais expressivo. Esse subgênero representou $58 \%$ da quantificação geral dos dativos, totalizando 298 ocorrências. A forma mais produtiva foi do paradigma de $t u$, o clítico te $(55,7 \%)$. Esse alto índice nesse paradigma se deve ao maior nível de intimidade entre os missivistas. O uso do clítico lhe $(15,1 \%)$, que foi predominante nas cartas de amigo e de família, perdeu espaço nas cartas de amor. Das formas dativas preposicionadas, a que mais se destacou foi a forma com preposição $+t i(15,5 \%)$. As formas $a$ você $(2,7 \%)$, para você $(7,4 \%)$, a ti $(2,7 \%)$ e para ti (zero ocorrência) tiveram um desempenho menor, assim como nos dois subgêneros analisados anteriormente.

\section{Considerações finais}

A análise das formas do paradigma $t u$ e você no contexto morfossintático dativo, considerando as condições de produção e os subgêneros da carta pessoal foi obtida a partir do levantamento da performance das cartas pessoais pernambucanas, pois é nesse processo que, ao considerarmos as condições de produção, podemos verificar a influência do perfil dos missivistas nas relações estabelecidas com seus interlocutores. Para isso, foi feita uma análise considerando a proximidade e a distância comunicativas, as relações de simetria e assimetria entre os missivistas e como as formas dos paradigmas de tu e você se comportam no contexto morfossintático dativo.

Este estudo, assim como em estudos anteriores, mostrou que em Pernambuco o clítico the disputa, quase que de igual para igual, com o clítico te nas ocorrências do dativo, corroborando a ideia de que "existe uma nítida correlação entre a forma usada na posição de sujeito da carta e as formas de complemento dativo: formas dos paradigmas de $t u$ e de você são mais frequentemente encontradas em cartas de sujeito tu-exclusivo e cartas de sujeito vocêexclusivo, respectivamente" (LOPES et al, 2018, p 183). 
Volume 15 - Número 1 - jan/jul de 2020

No que diz respeito ao subgênero e às relações simétricas e assimétricas, as cartas de família apresentaram uma incidência maior do clítico lhe $(65 \%)$ em relação a te com $(19,3 \%)$. Essas missivas enviadas de pai/mãe para filho/a e vice-versa correspondem a relações assimétricas. $\mathrm{O}$ mesmo ocorreu com as cartas de amigo, cuja forma dativa mais produtiva foi o lhe $(65 \%)$, seguido do te (14\%). Nestas cartas as relações são simétricas. Seguindo o mesmo padrão do subgênero carta de família, as carta e amigo apresentaram a predominância do paradigma de você no contexto dativo. Esse emprego está relacionado ao caráter híbrido dessa forma pronominal, ora mais cerimoniosa, ora mais íntima em se tratando de subgêneros marcados pela alternância da simetria e da assimetria. Quanto às cartas de amor, cujas relações, em tese, são mais simétricas, os resultados foram expressivos no sentido da predominância do paradigma de tu, com a ocorrência de $55,7 \%$ do clítico te, um resultado que pode ser justificado pelo maior grau de intimidade entre os missivistas.

Este artigo, em sua totalidade, visa contribuir não somente para a ampliação do corpus pernambucano de cartas pessoais, mas também com dados sobre o dativo acerca das variações identificadas nas cartas pessoais pernambucanas dos séculos XIX e XX e do estudo dos subgêneros textuais como forma de aprofundar o olhar diante de uma forma linguística em estudo, uma vez que o estudo do gênero carta pessoal possibilita a compreensão da variação da língua portuguesa em sua forma mais próxima da espontaneidade.

\section{Referências}

BROWN, R.; GILMAN, A. The pronouns of power and solidarity. In: SEBEOK, T. A. Style in Language. Massachusetts: Ed. MIT Press, 1960, p. 253-276.

BROWN, L.; LEVINSON, S. Politeness: some universal in language usage. Cambridge: Cambridge University, 1987.

COSTA, A. C. Ação - Formulação - Tradição: A correspondência de Câmara Cascudo a Mário de Andrade de 1924 a 1944, entre proximidade e distância comunicativa. In: MARTINS, Marco Antonio; TAVARES, Maria Alice (Org.). História do português Brasileiro no Rio Grande do Norte: análise linguística e textual da correspondência de Luís da Câmara Cascudo a Mário de Andrade - 1924 a 1944. Natal: EDUFRN, 2012.

GOMES, V. S. Tradições discursivas, variação e mudança no sistema pronominal de tratamento do português brasileiro em cartas pessoais pernambucanas (séculos XIX e XX). Relatório de atividades acadêmicas do Estágio Pós-Doutoral em Letras Vernáculas. Universidade Federal do Rio de Janeiro, Rio de Janeiro, 2014.

GOMES, V. S.; LOPES, C. R. S. Variação entre formas dos paradigmas de tu-você em cartas pernambucanas dos séculos XIX e XX. In: Revista do GELNE. v.16, p.1 - 15, 2014.

KOCH, P. Diskurstraditionen:zu ihrem sprachtheoretischen Status und ihrer Dynamik. In: FRANK, Barbara; HAYE, Thomas; TOPHINKE, Doris (Orgs.). Gattungen mittelalterlicher Schriftlichkeit. Tradução: Profa. Dra. Alessandra Castilho da Costa (UFRN). Tübingen: Narr 1997. p. 43-79.

LABOV, W. Padrões sociolinguísticos. São Paulo: Parábola Editorial, 2008.

LOPES, C. R. et al. A reorganização do sistema pronominal de $2^{a}$ pessoa na história do português brasileiro: outras relações gramaticais. In: LOPES, C. R.; CASTILHO, A. T. (Orgs). História do português brasileiro: mudança sintática das classes de palavra: perspectiva funcionalista. São Paulo: Contexto, 2018. 
Volume 15 - Número 1 - jan/jul de 2020

RUMEU, M. C. B.; OLIVEIRA, T. L. A expressão da 2a pessoa do singular em contextos de complementação e de adjunção: retratos do encaixamento estrutural e social. In: Linguística, v. 32, n. 2, p. 25-46, 2016.

SILVA, Aldeir Gomes da. Os subgêneros da carta pessoal em correspondências pernambucanas do século XX. Dissertação (Mestrado) - Universidade Federal de Pernambuco, Centro de Artes e Comunicação. Letras, 2018.

SOUZA, C. D.; OLIVEIRA, T. L. A representação da $2^{\mathrm{a}}$ pessoa nas posições de complemento: o papel da categoria social. In: Work. Paper. Linguística, 13(2): 100-120, Florianópolis, abr./jul., 2013.

SOUZA, J. P. F. Mapeando a entrada do você no quadro pronominal: análise de cartas familiares dos séculos XIX-XX. Rio de Janeiro: UFRJ - FL, 2012.

WEINREICH, U.; LABOV, W.; HERZOG, M. L. Fundamentos empíricos para uma teoria da mudança linguística. Tradução Marcos Bagno. São Paulo: Parábola Editorial, 2006.

Submetido em $28 / 05 / 20$

Aceito em 10/08/20 